\title{
Editorial
}

\section{Supercritical Water-Cooled Reactors}

\author{
Jiejin Cai, ${ }^{1}$ Claude Renault, ${ }^{2}$ and Junli Gou ${ }^{3}$ \\ ${ }^{1}$ Sino-French Institute of Nuclear Engineering and Technology, Sun Yat-sen University, Zhuhai, Guangdong 519082, China \\ ${ }^{2}$ INSTN/PSNE, The French Alternative Energies and Atomic Energy Commission (CEA) Saclay, 91191 Gif-sur-Yvette, France \\ ${ }^{3}$ School of Nuclear Science and Technology, Xian Jiaotong University, Xian, Shaanxi 710049, China
}

Correspondence should be addressed to Jiejin Cai; chiven77@hotmail.com

Received 24 July 2014; Accepted 24 July 2014; Published 18 August 2014

Copyright (C) 2014 Jiejin Cai et al. This is an open access article distributed under the Creative Commons Attribution License, which permits unrestricted use, distribution, and reproduction in any medium, provided the original work is properly cited.

Supercritical water-cooled reactor (SCWR) is the watercooled reactor using supercritical pressure water as coolant [1]. It is considered as one of the promising Generation IV reactors, due to its advantages of plant simplification and high thermal efficiency $[2,3]$.

Several design concepts of SCWRs have been proposed: (a) supercritical water-cooled thermal neutron reactor; (b) supercritical water-cooled fast neutron reactor; (c) supercritical water-cooled mixed neutron spectrum reactor; (d) supercritical water-cooled pebble bed reactor; (e) supercritical heavy-water-cooled reactor. The detailed design parameters of some typical SCWR concepts around the world are summarized in Table 1 [4]. Recently, the use of thorium in the SCWRs has been investigated $[5,6]$.

The advantages of the SCWRs are shown as follows [1].

(i) Supercritical water has excellent heat transfer properties allowing a high power density, a small core, and a small containment structure.

(ii) The use of a supercritical Rankine cycle with its typically higher temperatures improves efficiency (would be $\sim 45 \%$ ).

(iii) This higher efficiency would lead to better fuel economy and a lighter fuel load, lessening residual (decay) heat.

(iv) SCWR is typically designed as a once-through, direct cycle, whereby steam or hot supercritical water from the core is used directly in a steam turbine, which makes the design simple.

(v) Water is liquid at room temperature, cheap, nontoxic, and transparent, simplifying inspection and repair (compared to liquid metal cooled reactors). (vi) A fast SCWR could be a breeder reactor which could burn the long-lived actinide isotopes.

(vii) A heavy-water SCWR could breed fuel from thorium (4x more abundant than uranium), with increased proliferation resistance over plutonium breeders.

Some challenges in SCWRs are the subjects of research work which need us to research, among which are the following [4-7].

(i) Lower water inventory (due to compact primary loop) means less heat capacity to buffer transients and accidents (e.g., loss of feedwater flow or large break loss of coolant accident) resulting in accident and transient temperatures that are too high for conventional metallic cladding.

(ii) Higher pressure combined with higher temperature and also a higher temperature rise across the core result in increased mechanical and thermal stresses on vessel materials that are difficult to solve.

(iii) The coolant greatly reduces its density at the exit of the core, resulting in a need to place extra moderator there.

(iv) Extensive material development and research on supercritical water chemistry under radiation are needed.

(v) Special start-up procedures are needed to avoid instability before the water reaches supercritical conditions.

(vi) A fast neutron SCWR requires a relatively complex reactor core design in order to achieve a negative void coefficient. 
TABLE 1: Some typical SCWR concepts around the world.

\begin{tabular}{|c|c|c|c|c|c|c|c|}
\hline Name & Proposed by & Design concept & Moderate & $\begin{array}{l}\text { Rated } \\
\text { power } \\
(\mathrm{MW})\end{array}$ & $\begin{array}{c}\text { Outlet } \\
\text { temperature } \\
\left({ }^{\circ} \mathrm{C}\right)\end{array}$ & $\begin{array}{l}\text { Pressure } \\
(\mathrm{MPa})\end{array}$ & $\begin{array}{c}\text { Net efficiency } \\
(\%)\end{array}$ \\
\hline W21 & Tokyo University & $\begin{array}{l}\text { Thermal neutron } \\
\text { spectrum SCWR }\end{array}$ & $\mathrm{H}_{2} \mathrm{O}$ & 1570 & 508 & 25 & 44 \\
\hline TWG1 & Water TWG (Japan) & $\begin{array}{c}\text { Fast neutron } \\
\text { spectrum SCWR }\end{array}$ & $\mathrm{H}_{2} \mathrm{O}$ & 1728 & Alternative & Alternative & $38 \sim 45$ \\
\hline W6-1 & \multirow{4}{*}{ AECL (Canada) } & CANDU-X-MARK1 & \multirow{4}{*}{$\mathrm{D}_{2} \mathrm{O}$} & 910 & 430 & 25 & 41 \\
\hline W6-2 & & CANDU-XNC & & 370 & 400 & 25 & 41 \\
\hline W6-3 & & CANDU-ALX1 & & 950 & 450 & 25 & 40.6 \\
\hline W6-4 & & CANDU-X-ALX2 & & 1143 & 650 & 25 & 45 \\
\hline- & Europe & HPLWR & $\mathrm{H}_{2} \mathrm{O}$ & 1000 & 500 & 25 & 44 \\
\hline - & INEL (USA) & $\begin{array}{l}\text { Thermal neutron } \\
\text { spectrum SCWR }\end{array}$ & $\mathrm{H}_{2} \mathrm{O}$ & 1600 & 500 & 25 & 44 \\
\hline B500SKD1 & Russia & Integrative SCWR & $\mathrm{H}_{2} \mathrm{O}$ & 515 & 381 & 23.6 & 38 \\
\hline
\end{tabular}

In order to help readers understand the development of the SCWRs in the world, we sponsored a special issue on the supercritical water-cooled reactor and hoped to get some papers from the topics which include but are not limited to the following:

(i) reactor core and fuel designs,

(ii) materials, chemistry, and corrosion,

(iii) thermal-hydraulics and safety analysis,

(iv) plant systems, structures, and components,

(v) computational fluid dynamics (CFD) and coupled codes,

(vi) neutronic properties,

(vii) balance of plant,

(viii) other applications.

Now the special issue is published, which includes 5 papers. The contents include a new concept of core design, like "A simplified supercritical fast reactor with thorium fuel," calculation code development, like "Preliminary development of thermal power calculation code $H$-power for a supercritical water reactor," "Code development in coupled PARCS/RELAP5 for supercritical water reactor," and flow distribution, one of the important issues of thermal hydraulics in the nuclear reactor, like "Core flow distribution from coupled supercritical water reactor analysis." It also contains some experimental results, like "Experimental investigation on flow-induced vibration of fuel rods in supercritical water loop." We hope that readers of this special issue will find not only the development status of SCWRs and updated reviews on SCWRs, but also the formulation of important questions to be resolved such as how to develop the codes for SCWRs.

Jiejin Cai

Claude Renault Junli Gou

\section{References}

[1] Y. Oka, S. Koshizuka, Y. Ishiwatari, and A. Yamaji, Super Light Water Reactors and Super Fast Reactors, Springer, New York, NY, USA, 2010.

[2] S. Liu and J. Cai, "Convergence analysis of neutronic/thermohydraulic coupling behavior of SCWR," Nuclear Engineering and Design, vol. 265, pp. 53-62, 2013.

[3] S. Liu and J. Cai, "Neutronic and thermohydraulic characteristics of a new breeding thorium-uranium mixed SCWR fuel assembly," Annals of Nuclear Energy, vol. 62, no. 1, pp. 429-436, 2013.

[4] X. Yang, G. H. Su, W. Tian, J. Wang, and S. Qiu, "Numerical study on flow and heat transfer characteristics in the rod bundle channels under super critical pressure condition," Annals of Nuclear Energy, vol. 37, no. 12, pp. 1723-1734, 2010.

[5] S. Liu and J. Cai, "Neutronics assessment of thorium-based fuel assembly in SCWR," Nuclear Engineering and Design, vol. 260, pp. 1-10, 2013.

[6] S. Liu and J. Cai, "Design \& optimization of two breeding thorium-uranium mixed SCWR fuel assemblies," Progress of Nuclear Energy, vol. 70, pp. 6-19, 2014.

[7] Ph. Marsault, C. Renault, G. Rimpault, P. Dumaz, and O. Antoni, "Pre-design studies of SCWR in fast neutron spectrum: evaluation of operating conditions and analysis of the behavior in accidental situations," in Proceedings of the International Conference of Asian Political Parties (ICAPP '04), Pittsburgh, Pa, USA, June 2004. 


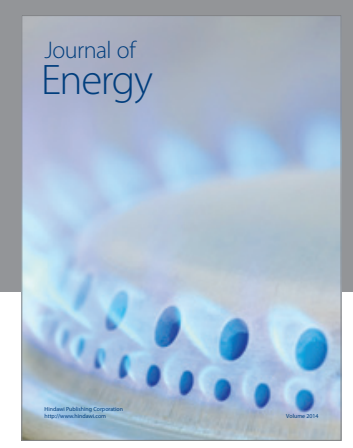

Journal of

Industrial Engineering
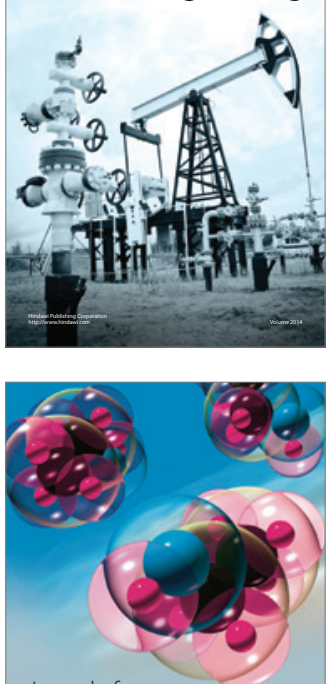

Fuels
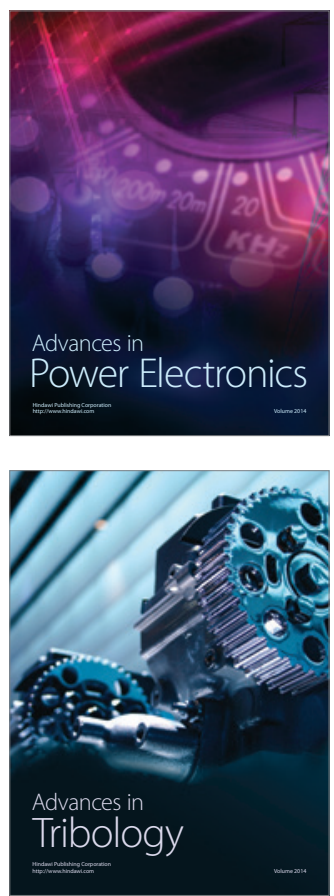

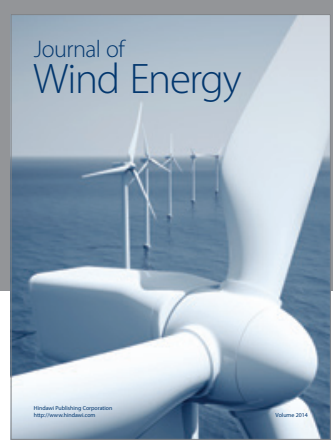

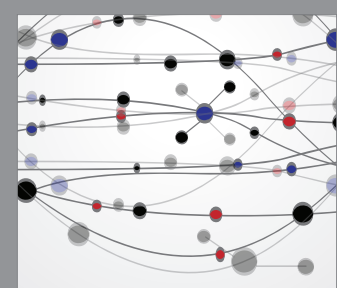

The Scientific World Journal

Submit your manuscripts at http://www.hindawi.com

Journal of

Structures
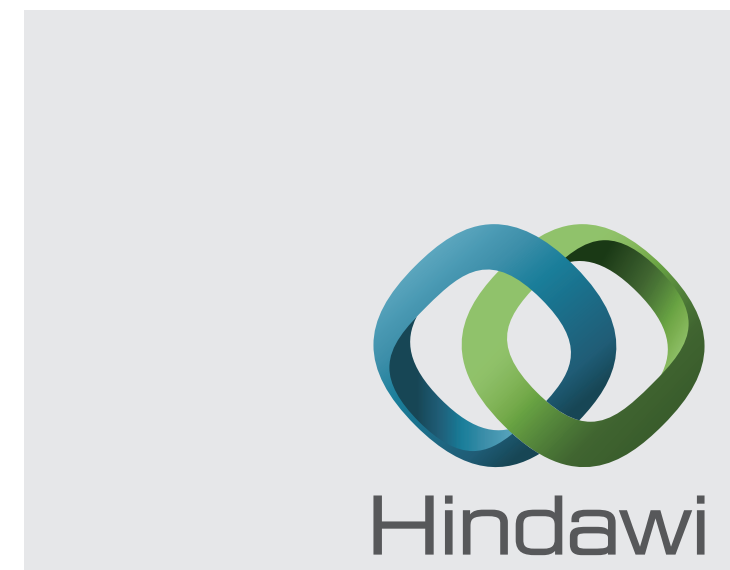

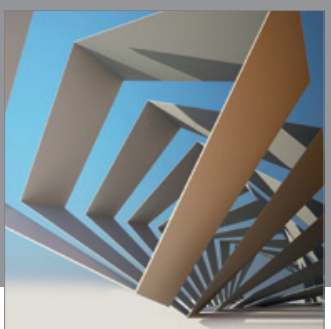

Rotating

Machinery
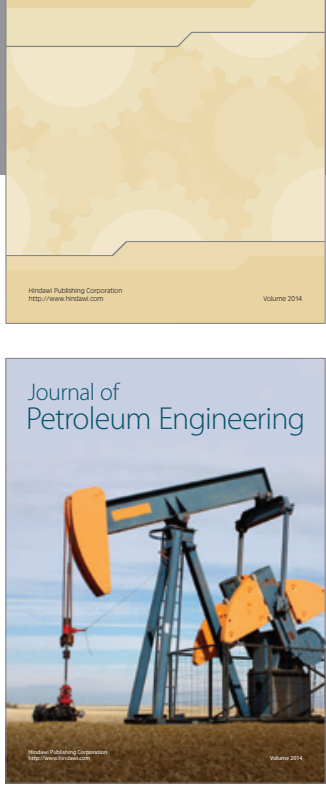

Journal of

Solar Energy
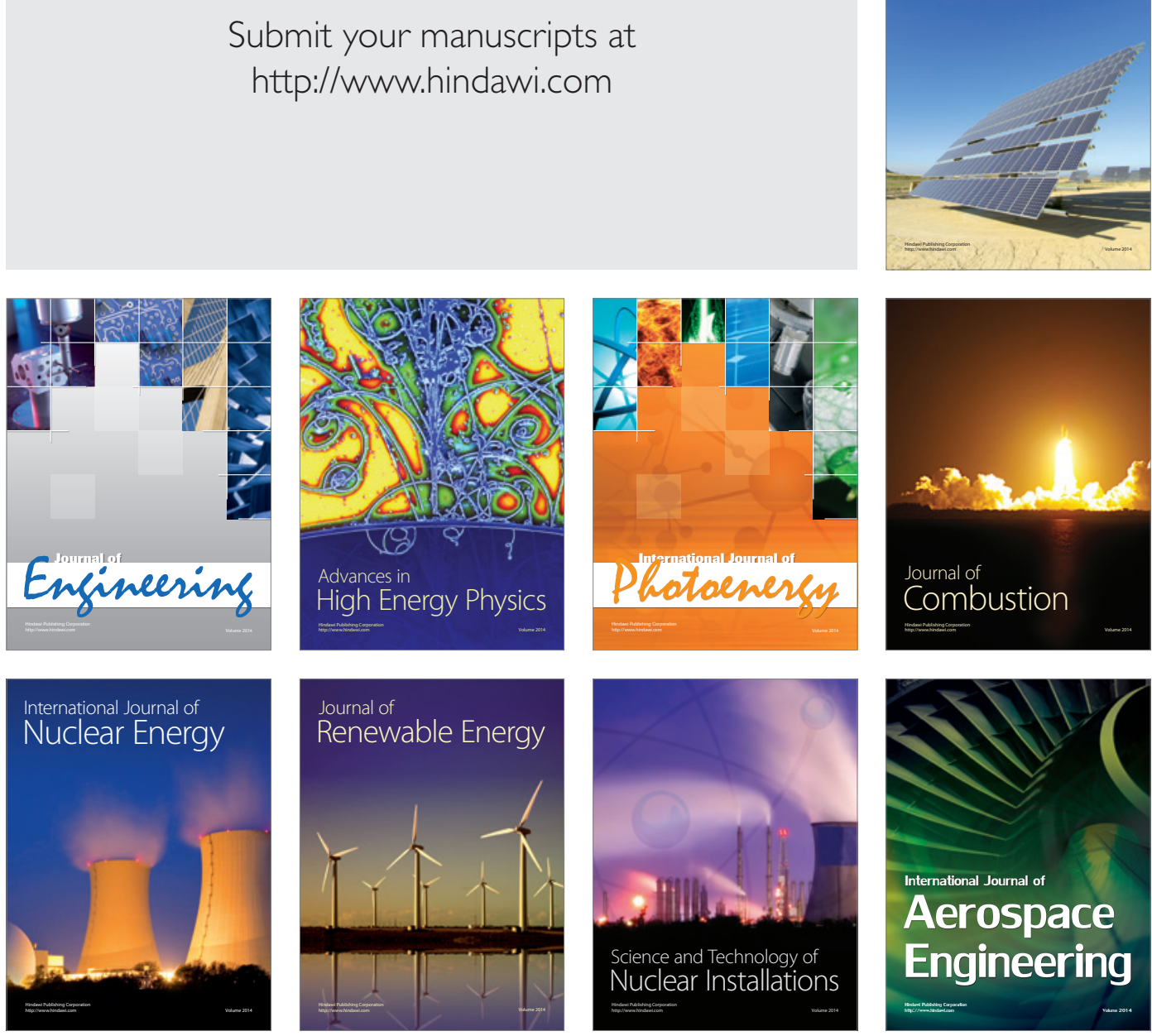